\title{
Percepção dos habitantes do município de Pindamonhangaba/SP acerca das dimensões de cidades inteligentes
}

Carlos Silvio Herculano ${ }^{1}$

Marcela Barbosa de Moraes²

Edson Aparecida de Araújo Querido Oliveira ${ }^{3}$

Submissão: 20/06/2021 Aceite: 12/09/2021

\begin{abstract}
Resumo
O crescimento desordenado da população em áreas urbanas sem um planejamento adequado provoca problemas econômicos e sociais. Há evidências que a Gestão pública não oferece um atendimento de qualidade, não consegue atender a demanda da população além do desafio de promover a igualdade social. Estudos recentes demonstram a aplicação de cidades inteligentes para ajudar a gestão pública a minimizar estes problemas. $O$ objetivo geral deste artigo é diagnosticar as dimensões de cidades inteligentes por meio da percepção dos habitantes do município de Pindamonhangaba/SP. Para tanto, utilizou-se como abordagem metodológica uma pesquisa quantitativa de caráter descritiva obtidas por meio da aplicação de questionário estruturado com questões fechadas aos habitantes. Optouse pela amostragem probabilística, a pesquisa do tipo survey (questionário). 0 processo de análise de dados se deu por meio da estatística descritiva. Pode-se concluir que para melhorar a prestação de serviços à população, além de mudar a visão dos habitantes de Pindamonhangaba, é importante a criação de novas políticas públicas para interação do governo com a população com projetos de uso da tecnologia em serviços prestados à sociedade, como na saúde, na educação, transporte e segurança e entre outros.
\end{abstract}

Palavras-chave: Desenvolvimento Regional. Planejamento Urbano. Gestão de Cidades. Cidades Inteligentes.

\section{Perception of the inhabitants of the municipality of Pindamonhangaba/SP about the dimensions of smart cities}

\begin{abstract}
Disorderly population growth in urban areas without proper planning causes economic and social problems. There is evidence that public management does not provide quality care, cannot meet the population's demand, in addition to the challenge of promoting social equality. Recent studies demonstrate the application of smart cities to help public management to minimize these problems. The general objective of this paper is to diagnose the dimensions of smart cities through the perception of the inhabitants of the city of Pindamonhangaba - SP. Therefore, quantitative descriptive research was used as a methodological approach, obtained through the application of a structured questionnaire with closed questions to the inhabitants. We opted for probabilistic sampling, the survey type research (questionnaire). The data analysis process took place through descriptive statistics. It can be concluded that to improve the provision of services to the population, in addition to changing the view of the inhabitants of Pindamonhangaba, it is important to create new public policies for government interaction with the population with projects for the use of technology in services provided to society, as in health, education, transport and security, among others.
\end{abstract}

Keywords: Regional Development. Urban Planning. Cities Management. Smart Cities

\footnotetext{
${ }^{1}$ Mestrado em Gestão e Desenvolvimento Regional (UNITAU). E-mai: carloherculano@gmail.com

${ }^{2}$ Pós-doutoranda no Centro de Sínteses Cidades Globais (IEA/USP) e Doutorado em Administração (UNINOVE). Professora do Programa de Pós-Graduação em Desenvolvimento Regional da Universidade de Taubaté (UNITAU). https://orcid.org/0000-0001-8043-1270 E-mail: marcelabmoraes@gmail.com

${ }^{3}$ Doutorado em Organização Industrial (ITA). Professor e Coordenador do Programa de Pós-Graduação em Desenvolvimento Regional da Universidade de Taubaté (UNITAU). http://orcid.org/0000-0001-9336-4249 E-mail: edsonaaqo@gmail.com
} 


\section{Introdução}

Projeções realizadas pela United Nations em 2018, indicam que no ano de 2017 a população mundial atingiu 7,6 bilhões de pessoas e que nos próximos 40 anos as populações urbanas crescerão em mais de 2 bilhões de pessoas, fazendo a população global ultrapassar os 9 bilhões de habitantes, sendo que mais de 65\% viverão nas áreas urbanas das cidades (UNITED NATIONS, 2018). Segundo dados do IBGE, em 2010, 84,4\% da população brasileira vivem nas áreas urbanas, e a cidade de Pindamonhangaba apresenta uma concentração ainda maior, 96,4\% de seus habitantes vivendo em áreas urbanas.

Com a pandemia gerada pelo COVID-19, ficou evidente muitos problemas socioeconômicos, problemas de desenvolvimento, problemas de planejamento das cidades, dificuldades sociais, principalmente em grandes concentrações de pessoas em ambiente estritamente urbanos (WEISS; BERNARDES; CONSONI, 2017; EVANS et al., 2019; ALLAM; JONES, 2020). Batagan (2011) e Weiss, Bernardes e Consoni (2017) relatam que o aumento populacional impacta na qualidade de vida das pessoas e no desenvolvimento urbano sustentável. Alguns autores relatam que as favelas são frutos do êxodo rural e com as favelas a precariedade do esgotamento sanitário (LEFEBVRE, 2011; SARAIVA, 2007; MORAES et al., 2020).

Segundo diversos autores a dificuldade na gestão dos resíduos, escassez de recursos, poluição do ar, problemas de saúde humana, congestionamentos de trânsito, infraestruturas inadequadas, deterioradas e antigas e entre outros são problemas relacionados a urbanização sem planejamento urbano, pois para melhorar a qualidade de vida dos habitantes das cidades, é melhorar o funcionamento das cidades (CHOURABI et al. 2012; DIAS et al., 2018; LUCAS; MORAES, 2019).

Mas como melhorar o funcionamento das cidades? Talvez seja possível melhorar o funcionamento das cidades com planejamento espacial, ou com bases em TI (tecnologia da informação), talvez com excelência em educação (inteligência) de seus habitantes, uma boa 'governança', referindo-se à utilização de canais de comunicação entre governo e população, o e-governance ou e-democracy. Estas características nos remete as cidades inteligentes (GIFFINGER et al. 2007).

A melhora do desempenho urbano segundo Marsal-Llacuna, Colomer-Llinàs e MeléndezFrigola (2015) ocorre com o uso de dados, informações e TICs, fornecendo serviços mais eficientes aos cidadãos, monitorando e otimizando a infraestrutura existente, incrementando a 
colaboração entre diferentes atores econômicos e encorajando modelos de negócios inovativos tanto no setor privado quanto no setor público.

Para Albino, Berardi e Dangelico (2015), locais onde se promove integração de desenvolvimento entre diversos aspectos, sejam eles físicos ou virtuais, Qualidade de vida das pessoas em comunidade e o uso de TIC podem ser considerados uma cidade inteligente. Cidades inteligentes atreladas a sustentabilidade é o que defendem autores como Lazaroiu e Roscia (2012) ao descreverem o termo cidades inteligentes, como uma forma de viver e considerar a cidade, apoiada em TICs que podem ser integradas em uma solução para gestão da energia, água, segurança pública, mobilidade e gestão de resíduos.

Outros autores tratam o termo cidades inteligentes vinculando-os ao capital humano, como é o caso de Caragliu, Del Bo e Nijkamp (2011). Estes entendem que uma cidade inteligente deve ter investimentos em capital humano e social, em infraestrutura de comunicação tradicional (transportes) e moderna (TICS), combustíveis para o crescimento econômico sustentável e alta qualidade de vida, com efetiva gestão dos recursos naturais, por meio de uma governança participativa.

É importante ressaltar o destaque dados por alguns autores ao papel da infraestrutura fixa ou móvel das TICs, que contribuem para sua integração, além de proporcionar facilidades. Entre estas, citam dados em tempo real, ambiente de inovação aberta a seus usuários, soluções inovadoras bem como contribuindo para acelerar processos burocráticos (ODENDAAL, 2003; TOPPETA, 2010; SCHAFFERS et al., 2011; CRETU, 2012; LEE et al., 2013; AHAD et al., 2020).

Para Barriounevo et al. (2012) e Lombardi et al. (2012), o uso da tecnologia é recurso disponível de forma inteligente e coordenada para desenvolver centros urbanos integrados e habitáveis. A aplicação de TICs na educação é uma vertente da cidade inteligente no que tange a sustentabilidade. Espera-se, então, que a alta tecnologia utilizada para conectar as pessoas e criar um comércio mais sustentável, aliada à combinação de um modelo de governança inteligente que analisa o fluxo de informações e traduz isto em serviços para os cidadãos e para as empresas, pode melhorar a rapidez na identificação de problemas e corrigi-los rapidamente. A pronta resposta para se recuperar de desastres e a utilização de infraestruturas unificadas de TICS com enfoque na competitividade econômica social são aspectos de sustentabilidade ligados a cidades inteligentes citados por alguns autores (DUTTA et al. , 2011; HERNÁNDEZ-MUÑOZ et al., 2011; NAN; PARDO 2011; VELOSA, 2011; BAKICl et al., 2012).

Este trabalho tem seu embasamento teórico nas definições de Giffinger e Haindlmaer (2010) que conceitua cidades inteligentes em seis dimensões: economia, pessoas, governança, 
mobilidade, meio ambiente e qualidade de vida. São construídas sobre uma combinação inteligente de atitudes decisivas, independentes e conscientes dos atores que nelas atuam.

Nesse contexto, o presente artigo busca contribuir com as discussões sobre a gestão das cidades inteligentes e desenvolvimento urbano, principalmente no município de Pindamonhangaba-SP. Assim, a seguinte questão foi formulada para orientar esta pesquisa: Quais são as características econômicas, sociais, ambientais e tecnológicas que determinam uma Cidade Inteligente percebidas pelos habitantes de Pindamonhangaba-SP, por meio dos serviços públicos proporcionados?

\section{Cidades Inteligentes e suas definições}

De acordo com Selada e Silva (2014), Yigitcanlar et al. (2018), a constituição de 'cidades inteligentes' forma um novo paradigma urbano. Segundo Giffinger et al. (2007), o termo 'cidade inteligente' não descreve somente uma cidade com certos atributos, do mesmo modo também não se refere ao planejamento espacial tão somente, mas é usado com o objetivo de designar vários aspectos que vão desde uma cidade com bases em TI (tecnologia da informação) até uma cidade com excelência em educação (inteligência) de seus habitantes.

Dessa forma vários aspectos são considerados na conformação de uma 'cidade inteligente', como por exemplo, em relação à capacidade econômica e de geração de empregos de uma cidade, a qual desse modo se conforma em uma 'indústria inteligente', implicando, sobretudo nos domínios das tecnologias de comunicação, bem como em processos de produção, da mesma forma em relação a parques empresariais ou distritos industriais, o termo "cidade inteligente" também é utilizado (GIFFINGER et al., 2007; YIGITCANLAR; KANKANAMGE; VELLA, 2020).

Sendo assim uma 'cidade inteligente' também discute a moderna vida urbana e seus aglomerados, incluindo além das TICS (tecnologias de informação e comunicação), mas em especial, as modernas tecnologias de transporte e logística, por meio dos 'sistemas inteligentes de transportes' que melhoram o tráfego urbano e a mobilidade de seus habitantes (GIFFINGER et al., 2007).

Benevolo, Dameri e D’Auria (2016) e Ahad et al. (2020) salientam as várias abordagens em referência a 'cidades inteligentes', por meio de 'iniciativas inteligentes' e 'estratégias inteligentes' de ação sobre o território e à conformação urbana sob um conjunto de tópicos tais como: tratamento de resíduos à qualidade do ar, bem como da eficiência energética de edifícios 
até a transparência de dados governamentais em plataformas eletrônicas da administração municipal. Contudo, salientam que ainda se aborda o tema de forma modesta sobre a questão da qualidade de vida dos cidadãos, sua capacidade de solucionar os problemas urbanos e qual o desempenho dos projetos de 'cidades inteligentes'.

Giffinger et al. (2007) e ) e Ahad et al. (2020) também observam os demais aspectos que se referem à vida urbana sendo correlacionados ao conceito de 'cidades inteligentes', como a segurança, a sustentabilidade ambiental, o baixo consumo de recursos e a eficiência energética. Sendo assim demais campos de atuação são salientados no que diz respeito a uma 'cidade inteligente', como em relação à indústria, educação, interação entre seus habitantes, infraestrutura técnica e demais fatores tecnológicos, de comunicação e sensoriamento.

Para Benevolo, Dameri e D’Auria (2016), as 'cidades inteligentes tem suas raízes em diferentes correntes fundidas sob a ótica da 'cidade inteligente' em três tópicos:

- Cidade Digital: considerando a utilização efetiva das TIC (tecnologias de informação e comunicação) para criar redes de interconexão entre os cidadãos e organizações, partilhando assim dados e informações, sobre plataformas de serviços on-line. Deste modo Internet, Banda Larga e Dispositivos Inteligentes estão na base desta abordagem, se disseminando entre os cidadãos e apoiando as políticas públicas de o e-governance ou e-democracy, ou seja, de governo eletrônico sobre plataformas eletrônicas e democracia eletrônica por meio da transparência de dados e ações aos cidadãos.

- Cidade Verde: considera uma visão ecológica do espaço urbano, baseando-se no conceito de desenvolvimento sustentável, uma vez que a 'cidade' parte da concepção de um sistema potencialmente poluente em suas estruturas, edifícios, meios de transporte. Contudo as políticas verdes representam o papel de preservar o espaço físico, por meio da redução da 'pegada ambiental', reduzindo e gerenciando os resíduos de poluição e o consumo de energia, como também preservando e criando áreas verdes públicas como parques e jardins.

- Cidade do Conhecimento ou ainda Tecnópole: considera as políticas públicas que visam reforçar dados, informações e conhecimento disponíveis e produzidos no espaço urbano, em especial nas universidades e centros de pesquisa, como também em empresas, distritos inovadores e parques tecnológicos. Também considera a produção cultural presente em teatros e bibliotecas. 
Albino, Berardi e Dangelico (2015) observam que não há um único modelo de enquadramento para a caracterização de uma 'cidade inteligente', nem em tamanho e nem em ações e projetos desenvolvidos. Inicialmente o foco das 'cidades inteligente' estava na importância das novas tecnologias de informação e comunicação aliadas as infraestruturas dentro das cidades.

Sendo assim, o Instituto da Califórnia para 'Comunidades Inteligentes' foi um dos primeiros a atribuir o conceito de que comunidades poderiam se tornar inteligentes à medida que fossem projetadas para receberem as tecnologias da informação. Bem como o centro de governança da Universidade de Ottawa volta-se para a ideia de que as 'cidades inteligentes' não devem ser demasiadamente orientadas para a questão tecnológica, mas sim ter uma abordagem fortemente orientada para a governança, enfatizando o capital social e as relações humanas no desenvolvimento urbano (ALBINO; BERARDI; DANGELICO, 2015).

Do mesmo modo, Harrison e Donnely (2011) caracterizam que o termo 'cidade inteligente' denota uma cidade instrumentada, interligada e inteligente, capacitada em interagir de forma real por meio da utilização de sensores, contadores, aparelhos, dispositivos pessoais, e demais sensores, integrando dados em uma plataforma de comunicação que permita que tais informações sejam inseridas e georreferenciadas em serviços de análise, modelagem, otimização e visualização de melhores condições aos seus usuários.

Ao observar Hollands (2008), pode-se resumir a caracterização de uma 'cidade inteligente' em quatro tendências essenciais a todos os modelos possíveis, dentre as quais destaca-se: a utilização intensiva de tecnologias de informação e comunicação; a ênfase no desenvolvimento urbano moldado pelas grandes empresas multinacionais; o foco nas indústrias de elevada intensidade tecnológica; e, a preocupação com a eficiência energética e preservação de recursos naturais.

Na dimensão do planejamento urbano, as 'cidades inteligentes' são tratadas e pensadas segundo uma visão e direção estratégica, onde governo e agencias publicas adotam a noção de inteligência para distinguir políticas e programas que promovam o desenvolvimento sustentável por meio do crescimento econômico e da melhoria de qualidade de vida de seus cidadãos (BALLAS, 2013; LUCAS; MORAES 2019).

Com o objetivo de concluir uma abordagem que contemple os diversos aspectos de uma 'cidade inteligente', Selada e Silva (2014) estabelecem que uma 'cidade inteligente' é definida como uma cidade ambientalmente consciente, que utiliza a tecnologia da informação para utilizar a energia e demais recursos de forma consciente e sustentável, procurando estabelecer 
um bom nível de qualidade de vida para os seus cidadãos, bem como um crescimento econômico favorável, recorrendo a técnicas avançadas de TIC (tecnologias de informação e comunicação).

Sendo assim, Giffinger et al. (2007) estabelecem de forma clara seis dimensões para a conceituação de uma 'cidade inteligente', sendo: economia inteligente, pessoas inteligente, governança inteligente, mobilidade inteligente, ambiente inteligente e modo de vida inteligente como as abordagens a seguir.

1. Economia Inteligente. Inclui fatores em relação a competitividade econômica, como inovação, o empresariado, as marcas, a produtividade e a flexibilidade do mercado de trabalho, assim como a integração no mercado nacional.

2. Pessoas Inteligentes. Este aspecto não faz referência somente ao nível de qualificação ou de educação dos cidadãos, mas também se refere ao nível de qualidade das interações sociais, relativas à integração e à vida pública dos habitantes, assim como em relação à abertura ao mundo "exterior", ou seja, em relação às demais regiões com que se relaciona.

3. Governança Inteligente. Compreende aspectos políticos de participação e de serviços voltados ao cidadão, assim como o bom funcionamento administrativo da gestão pública.

4. Mobilidade Inteligente. A acessibilidade local e internacional são aspectos importantes da mobilidade inteligente, por meio da disponibilidade de tecnologias de informação e comunicação, bem como de tecnologias modernas e sistemas de transportes sustentáveis.

5. Ambiente Inteligente. $\mathrm{O}$ ambiente inteligente é descrito pela presença de condições ambientais satisfatórias, como clima, espaços verdes, baixos índices de poluição, gestão eficiente de recursos naturais e proteção ao meio ambiente.

6. Modo de Vida Inteligente. Finalmente corresponde aos aspectos de qualidade de vida, como a oferta de cultura, a saúde, a segurança, a habitação e o turismo.

Dessa forma, estas características e fatores constituem o enquadramento para a avaliação de desempenho de uma cidade como sendo uma 'cidade inteligente'. Do mesmo modo, Lucas e Moraes (2018) salientam aspectos semelhantes para a definição de uma 'cidade inteligente', ressaltando que a gestão eficiente de recursos e espaço, a segurança e bem-estar dos cidadãos e a aplicação de políticas flexíveis são essencialmente o que define uma 'cidade 
inteligente', determinando de forma semelhante sete aspectos constituintes na conformação de uma 'cidade inteligente'. É precisamente este o marco teórico desta pesquisa.

\section{Metodologia}

Esta pesquisa tem um caráter descritivo, pois descreve as dimensões de uma cidade inteligente percebidas pelos habitantes de Pindamonhangaba, com enfoque quantitativo. Utilizase, também, a pesquisa tipo survey (pesquisa em grande escala), apresentando descrições do tamanho da pesquisa, tipo de amostra, tipo de coleta, perguntas e opiniões, avaliação de processos e inferências (BABBIE, 1999).

A área de realização desse estudo foi à cidade de Pindamonhangaba - SP, devido a sua importância econômica, histórica e social na região, o município está localizado na Região Metropolitana do Vale do Paraíba e Litoral Norte (RMVPLN). A cidade de Pindamonhangaba - SP se destaca nacionalmente pela sua diversa e intensa atividade econômica no âmbito econômico a produção industrial é altamente desenvolvida, predominando principalmente o setor de reciclagem de alumínio e fabricação de tubos.

Para a seleção da amostra para aplicação do questionário foi utilizado os dados da população da cidade de Pindamonhangaba referente ao Censo de 2010 realizado pelo IBGE. Deste modo, o município de Pindamonhangaba possuía 146.995 habitantes (IBGE, 2010). Levando em consideração o número de pessoas da população em estudo, habitantes de Pindamonhangaba - SP; margem de Erro = 5\% ; nível de confiança $=95 \%$ e heterogeneidade de 50\%, obteve-se uma amostra de 384 indivíduos.

O instrumento utilizado para o desenvolvimento deste artigo foi a pesquisa por meio de questionário, adaptado de estudos realizados por Giffinger et al. (2007) pela universidade de Viena. O questionário foi elaborado em formato de lista, composto de perguntas estruturadas e fechadas. A cada questão possui somente uma resposta dentre as cinco alternativas disponível, foi adotado a utilização balanceada para se empregar a escala Likert. O questionário foi elaborado em duas seções, sendo a primeira, nomeadas com questões demográficas; e, na segunda seção, composta por 82 perguntas relacionadas aos domínios de inteligência, nomeado de questões gerais.

No período de novembro de 2019 a fevereiro de 2020, a pesquisa foi aplicada em espaços públicos como o parque da Juventude, o Bosque da Princesa, pontos de ônibus da região central do município e nas ruas do bairro de Moreira Cesar e do bairro do Araretama, por serem bairros 
de densidade populacional altas segundo a prefeitura. Durante esse período foram aplicados, entre impressos e eletrônicos, um total de 387 questionários válidos, todavia, foram enviados 500 questionários, sendo descartados 113 formulários devido à falta de respostas e motivos de não enquadramento do público-alvo da pesquisa, neste caso, por exemplo, pessoas de outras cidades.

Na utilização do método eletrônico utilizou-se a plataforma de serviços Google Forms, que oferece uma interface de fácil compreensão e utilização do software para que se adapte a qualquer dispositivo, como celular, tablet, computador ou notebook. O endereço eletrônico do questionário foi distribuído pelas redes sociais whatsapp; facebook; menseger; e e-email.

A etapa da análise de dados quantitativos de pesquisa se deu a partir da organização dos dados, agrupando-os em tabelas, resumindo as principais estatísticas e por fim analisando e interpretando os dados. Utilizou-se o cálculo do ranking médio (RM), para avaliar as respostas válidas e excluir as abstenções da frequência das respostas dos entrevistados.

Esse ranking é composto pela média ponderada (MP), em que se divide o total da frequência de cada opinião, para cada pergunta, pelo peso relativo que foi atribuído de 1 a 5 dentro da escala Likert de 5 pontos (OLIVEIRA, 2005).

Para calcular o RM utiliza-se a equação 1:

$$
(\mathrm{RM})=\Sigma(\mathrm{fi} . \mathrm{Vi}) /(\mathrm{NR})
$$

Em que:

$\mathrm{fi}$ = frequência total observada em cada opinião para cada questão

$\mathrm{Vi}=$ valor de cada resposta ou peso atribuído

$N R$ = número de respostas: opiniões válidas

Quanto mais próximo o resultado for de cinco, maior será o nível de identificação e satisfação do respondente, e quanto mais próximo for de um pior será a conceituação ou insatisfação relativa à questão. Acima de três o reconhecimento é positivo. Os resultados são analisados tomando como base as frequências relativas ao peso das respostas pertinentes a cada nível, totalizando uma média de avaliação: o ranking médio.

A fim de complementar ranking médio, calculou-se o desvio-padrão do conjunto de dados coletados. De acordo com Spiegel e Stephens (2000), o desvio-padrão é uma medida de dispersão, ou seja, indica o quanto o conjunto de dados é uniforme. O autor acrescenta argumentando que quando o desvio-padrão é baixo significa que os dados do conjunto estão mais próximos da média. 


\section{Análise e Discussão dos Resultados}

Para responder à pergunta de pesquisa, esta seção está dividida em duas etapas. A primeira etapa descreveu o perfil dos respondentes utilizando a frequência e a segunda etapa descreveu, por meio da estatística descritiva, os aspectos relativos à: gestão pública, economia, ambiente, mobilidade e ao cotidiano do cidadão.

\subsection{Caracterização dos Respondentes}

Antes de iniciar a análise das dimensões de cidades inteligentes, é importante analisar o perfil dos respondentes que participaram da pesquisa e foi composto por cinco questões demográficas, a saber: gênero, faixa etária, escolaridade, ocupação e região que reside. $\mathrm{Na}$ análise referente ao gênero dos respondentes, conforme apresentado na tabela 1, observou-se que o gênero feminino foi predominante, representando $53,0 \%$ frente a $47,0 \%$ do masculino.

Tabela 1 - Gênero dos respondentes

\begin{tabular}{l|c|c|c|c}
\hline \multicolumn{1}{c|}{ Gênero } & Frequência & Porcentagem & Porcentagem válida & Porcentagem acumulativa \\
\hline Feminino & 205 & 53,0 & 53,0 & 53,0 \\
Masculino & 182 & 47,0 & 47,0 & 100,0 \\
Total & 387 & 100,0 & 100,0 & ---- \\
\hline
\end{tabular}

Fonte: Elaborado pelo autor

Os dados do gênero estão alinhados com o Censo Demográfico de 2010 realizado pelo IBGE (2010). De acordo com o Censo, a população do município de Pindamonhangaba em 2010 era constituída por $50,83 \%$ de mulheres (74.707) e $49,17 \%$ de homens (72.288).

Ao analisar a tabela 2, observa-se que $40,1 \%$ dos respondentes estão na faixa etária entre 26 e 40 anos, 36,7\% entre 41 e 65 anos e 18,3\% com até 25 anos. Esses dados também estão alinhados com o Censo, pois a faixa etária entre 26 e 40 anos representam 25,15\%, seguido de 24,38\% entre 41 e 65 anos e até 25 anos eram 8,51\% da população.

Tabela 2 - Faixa etária dos respondentes

\begin{tabular}{l|c|c|c|c}
\hline Faixa Etária & Frequência & Porcentagem & Porcentagem válida & Porcentagem acumulativa \\
\hline Até 25 anos & 71 & 18,3 & 18,3 & 18,3 \\
Entre 26 e 40 anos & 155 & 40,1 & 40,1 & 58,4 \\
Entre 41 e 65 anos & 142 & 36,7 & 36,7 & 95,1 \\
Acima de 65 anos & 19 & 4,9 & 4,9 & 100,00 \\
Total & 387 & 100,0 & 100,0 & --- \\
\hline
\end{tabular}

Fonte: Elaborado pelo autor 
No quesito nível de escolaridade dos respondentes, conforme exposto na tabela 3, verificou-se que $31,8 \%$ dos respondentes possuem ensino médio completo, $22,2 \%$ ensino médio incompleto e $13,7 \%$ ensino superior completo. Pode-se dizer que os respondentes fazem parte de uma parcela da população com um nível educacional que contribui para o desenvolvimento do município.

Tabela 3 - Nível de Escolaridade dos Respondentes

\begin{tabular}{l|c|c|c|c}
\hline Escolaridade & Frequência & Porcentagem & $\begin{array}{c}\text { Porcentagem } \\
\text { válida }\end{array}$ & $\begin{array}{c}\text { Porcentagem } \\
\text { acumulativa }\end{array}$ \\
\hline Não alfabetizado & 3 & 0,8 & 0,8 & 0,8 \\
Fundamental incompleto & 18 & 4,7 & 4,7 & 5,5 \\
Fundamental completo & 25 & 6,5 & 6,5 & 12,0 \\
Médio incompleto & 86 & 22,2 & 22,2 & 34,2 \\
Médio completo & 123 & 31,8 & 31,8 & 66,0 \\
Superior incompleto & 51 & 13,2 & 13,2 & 79,2 \\
Superior completo & 53 & 13,7 & 13,7 & 92,9 \\
Pós-graduado & 25 & 6,5 & 6,5 & 99,4 \\
Mestrado & 2 & 0,5 & 0,5 & 99,9 \\
Pós-doutorado & 1 & 0,1 & 0,1 & 100,0 \\
Total & 387 & 100,0 & 100,0 & --- \\
\hline
\end{tabular}

Fonte: Elaborado pelo autor

Ao analisar a tabela 4 , notou-se $56,6 \%$ dos participantes da pesquisa são empregados, 18,1\% são autônomos/profissionais liberais e 10,6\% estão desempregados.

Tabela 4 - Ocupação dos Respondentes

\begin{tabular}{l|r|r|r|r}
\hline \multicolumn{1}{c|}{ Ocupação } & Frequência & Porcentagem & $\begin{array}{c}\text { Porcentagem } \\
\text { válida }\end{array}$ & $\begin{array}{c}\text { Porcentagem } \\
\text { acumulativa }\end{array}$ \\
\hline Aposentado & 20 & 5,2 & 5,2 & 5,2 \\
Autônomo (Profissional Liberal) & 70 & 18,1 & 18,1 & 23,3 \\
Desempregado & 41 & 10,6 & 10,6 & 33,9 \\
Empregado & 219 & 56,6 & 56,6 & 90,4 \\
Empresário & 19 & 4,9 & 4,9 & 95,3 \\
Outros & 18 & 4,7 & 4,7 & 100,0 \\
Total & 387 & 100,0 & 100,0 & -- \\
\hline
\end{tabular}

Fonte: Elaborado pelo autor

Esse perfil vai ao encontro da característica econômica do município que é formada por várias indústrias, tais como: Aromax; Basell Poliolefinas; Brasbar/Dart Embalagens Descartáveis do Brasil; Confab Equipamentos; Gerdau (antiga unidade da Villares); Givi do Brasil; GV do Brasil; Latasa; Novelis; Pisani; Rogama; Tenaris; Tenaris Coating; Total Lubrificantes; Zodiac Farmacêutica; Zuiko Industria de Maquinas. 
A cidade de Pindamonhangaba não possui um zoneamento por bairros, desta forma com o objetivo de agrupar e facilitar a coleta de dados, foi feita a divisão dos bairros da cidade em quatro regiões, região 1, região 2, região 3 e região 4, esta divisão foi feita baseada na legislação municipal (№ 4.972 DE 16 DE OUTUBRO DE 2019).

Devido a esta divisão por região não ser de conhecimento dos habitantes de Pindamonhangaba, foi necessário elaborar um mapa ilustrativo da cidade, segregados por bairros e delimitado por estas regiões, este mapa foi disponibilizado junto com os questionários eletrônicos. Para os questionários impressos em papel, foi necessário confeccionar um banner de 1,5 metro de altura por 2 metros de comprimento que mostrava o mapa da cidade de Pindamonhangaba separado por bairro e região, que foi afixado nos locais onde eram aplicados os questionários para facilitar aos respondentes identificar os bairros onde residiam e a qual região pertenciam. Deste modo, questionou aos respondentes qual era a região que residia, conforme tabela 5 .

Tabela 5 - Região de Residência dos Respondentes

\begin{tabular}{l|r|c|c|c}
\hline & Frequência & Porcentagem & Porcentagem válida & Porcentagem acumulativa \\
\hline Região 1 & 102 & 26,4 & 26,4 & 26,4 \\
Região 2 & 122 & 31,5 & 31,5 & 57,9 \\
Região 3 & 55 & 14,2 & 14,2 & 72,1 \\
Região 4 & 108 & 27,9 & 27,9 & 100,0 \\
Total & 387 & 100,0 & 100,0 & ---- \\
\hline
\end{tabular}

Fonte: Elaborado pelo autor

Ao analisar a Tabela 5, verificou-se que 31,5\% dos respondentes residiam na região 2 que se localiza na zona leste do município e $27,9 \%$ dos respondentes residem na região 4, zona oeste, onde está localizado no distrito de Moreira César. Já, 26,4\% dos respondentes alegaram habitar na região 1, zona norte e na zona central definida como região 3 possui 14,2\% dos respondentes. Um limitante da pesquisa foi a dificuldade de equalizar as respostas nas regiões.

É importante destacar que os habitantes de Pindamonhangaba não sabiam em qual região residiam, mesmo com o auxílio do mapa. Deste modo, viu-se a necessidade da criação de uma nova questão (bairro) para que diminuísse o risco de os respondentes cometer um erro quando apontasse a região em que reside. Sendo assim, a questão não tem a finalidade de levar essa pesquisa a uma análise mais profunda, apenas de minimizar o erro na hora de apresentar a região em que o respondente reside. Assim, quando os participantes da pesquisa apresentavam o bairro de residência, foi possível fazer uma relação quando os dados fossem tratados entre 
bairro e a região correta, dessa forma garantindo a veracidade da questão cinco quando os dados fossem apresentados.

Em suma, pode-se dizer que a relação do perfil demográfico analisado nesta etapa da amostra populacional coletada, a presente pesquisa caracterizou a sua população e comparou com os dados oficiais do município, corroborando na validação dos objetivos dessa fase e contribuindo para a fundamentação da pesquisa nas próximas fases.

\subsection{Análise Descritiva das Dimensões de Cidades Inteligentes}

Após a e análise do perfil sociodemográfico, foi realizado o cálculo da média, ranking médio e desvio-padrão, que dimensionou o nível de satisfação apresentado nas respostas, sendo assim, classifica as frequências das respostas dos respondentes.

A primeira dimensão a ser analisada foi a Economia Inteligente, conforme tabela 6, que apresentou um ranking médio de 3,27, ou seja, os habitantes que participaram da pesquisa concordam parcialmente que a dimensão é importante para se formar uma cidade inteligente. Outro ponto importante é o grau de dispersão dos dados, observou-se que houve baixa dispersão dado ao baixo desvio-padrão.

Tabela 6 - Análise Descritiva da Dimensão Economia Inteligente

\begin{tabular}{|c|c|c|c|c|c|c|}
\hline Característica & $\begin{array}{c}\text { Fatores } \\
\text { (Variável Latente) }\end{array}$ & $\begin{array}{c}\text { Questões } \\
\text { (Variável } \\
\text { Observada) }\end{array}$ & Média & $\begin{array}{l}\text { Desvio- } \\
\text { Padrão }\end{array}$ & $\begin{array}{l}\text { Ranking } \\
\text { Médio do } \\
\text { Fator }\end{array}$ & $\begin{array}{c}\text { Ranking Médio } \\
\text { da } \\
\text { Característica }\end{array}$ \\
\hline \multirow{14}{*}{ 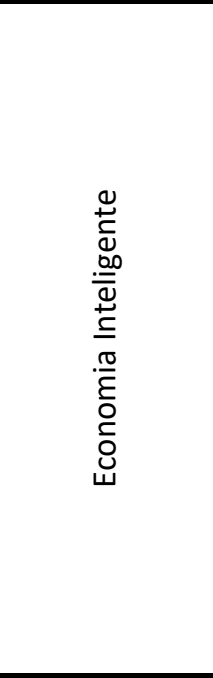 } & \multirow{3}{*}{ Espírito Inovador } & El_01 & 2,92 & 1,37 & \multirow{3}{*}{3,21} & \multirow{14}{*}{3,27} \\
\hline & & El_02 & 3,16 & 1,40 & & \\
\hline & & El_03 & 3,55 & 1,25 & & \\
\hline & \multirow{2}{*}{ Empreendedorismo } & El_04 & 3,07 & 1,42 & \multirow{2}{*}{3,25} & \\
\hline & & El_05 & 3,42 & 1,29 & & \\
\hline & \multirow{3}{*}{$\begin{array}{c}\text { Imagem econômica } \\
\text { de marcas }\end{array}$} & El_06 & 3,54 & 1,35 & \multirow{3}{*}{3,54} & \\
\hline & & El_07 & 3,35 & 1,38 & & \\
\hline & & El_08 & 3,75 & 1,23 & & \\
\hline & Produtividade & El_09 & 2,84 & 1,31 & 2,84 & \\
\hline & \multirow{3}{*}{$\begin{array}{l}\text { Flexibilidade do } \\
\text { mercado de } \\
\text { trabalho }\end{array}$} & El_10 & 3,48 & 1,29 & \multirow{3}{*}{3,44} & \\
\hline & & El_11 & 3,77 & 1,33 & & \\
\hline & & El_12 & 3,07 & 1,37 & & \\
\hline & \multirow{2}{*}{$\begin{array}{c}\text { Inserção } \\
\text { Internacional }\end{array}$} & El_13 & 3,13 & 1,39 & \multirow{2}{*}{3,33} & \\
\hline & & El_14 & 3,53 & 1,30 & & \\
\hline
\end{tabular}

Fonte: Elaborado pelo autor

A maior média dessa dimensão foi 'imagem econômica de marcas' de 3,54 que representa que os respondentes acreditam que a cidade é reconhecida pelo que produz e que existem 
muitas empresas que são reconhecidas nacionalmente. Como já mencionado a cidade possui várias empresas que emprega uma boa parcela da população do município.

Outra variável latente que merece destaque é 'flexibilidade do mercado de trabalho' que apresentou uma média de 3,44. Pode-se dizer que os cidadãos reconhecem que o município possui empresas multinacionais e que existem muitos trabalhadores formais e informais. De acordo com o Ministério do Trabalho e Emprego (MTE, 2019), Pindamonhangaba fechou o ano de 2019 com saldo positivo de 1069 vagas e os três setores que mais contribuíram para o desempenho do município foram serviços com 488 vagas, construção civil com 464, e indústria com 135.

Por outro lado, o fator que apresentou a menor média dessa dimensão foi 'espírito inovador' com valor de 3,21. Isto demostra que a população participante da pesquisa não se reconhece como criativa e que a cidade não investe em pesquisa e desenvolvimento. Um outro ponto importante desse fator é que, na percepção da população, a cidade não oferta serviços especializados, o que pode gerar baixos salários.

Na dimensão mobilidade urbana, na tabela 7, verificou-se a dimensão um ranking médio abaixo de 3, ou seja, de 2,52 e baixa dispersão dos dados. Isso significa que os habitantes consideram a mobilidade urbana do município regular.

Tabela 7 - Análise Descritiva da Dimensão Mobilidade Inteligente

\begin{tabular}{|c|c|c|c|c|c|c|}
\hline Característica & $\begin{array}{c}\text { Fatores } \\
\text { (Variável Latente) }\end{array}$ & $\begin{array}{c}\text { Questões } \\
\text { (Variável } \\
\text { Observada) }\end{array}$ & Média & $\begin{array}{l}\text { Desvio- } \\
\text { Padrão }\end{array}$ & $\begin{array}{l}\text { Ranking } \\
\text { Médio do } \\
\text { Fator }\end{array}$ & $\begin{array}{l}\text { Ranking Médio } \\
\text { da Característica }\end{array}$ \\
\hline \multirow{11}{*}{ 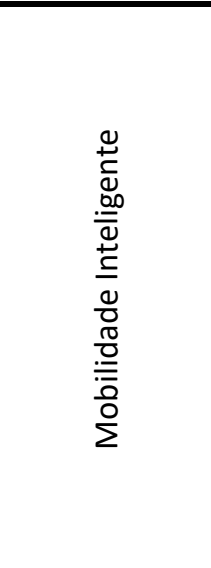 } & \multirow{3}{*}{ Acessibilidade local } & MI_01 & 2,96 & 1,43 & \multirow{3}{*}{2,89} & \multirow{11}{*}{2,52} \\
\hline & & MI_02 & 2,85 & 1,33 & & \\
\hline & & MI_03 & 3,12 & 1,38 & & \\
\hline & $\begin{array}{c}\text { Acesso } \\
\text { Intermunicipal } \\
\end{array}$ & MI_04 & 3,28 & 1,36 & 1,67 & \\
\hline & \multirow{2}{*}{$\begin{array}{l}\text { Disponibilidade de } \\
\text { infraestrutura TIC }\end{array}$} & MI_05 & 2,52 & 1,40 & \multirow{2}{*}{3,45} & \\
\hline & & MI_06 & 3,04 & 1,36 & & \\
\hline & \multirow{5}{*}{$\begin{array}{l}\text { Transporte público } \\
\text { sustentável, } \\
\text { inovador e seguro }\end{array}$} & MI_07 & 3,42 & 1,23 & \multirow{5}{*}{2,06} & \\
\hline & & MI_08 & 2,70 & 1,39 & & \\
\hline & & MI_09 & 2,79 & 1,41 & & \\
\hline & & MI_10 & 2,72 & 1,36 & & \\
\hline & & MI_11 & 2,81 & 1,44 & & \\
\hline
\end{tabular}

Fonte: Elaborado pelo autor

A variável latente que apresentou a menor média foi o acesso intermunicipal com o valor de 1,67. Pode-se dizer que na opinião dos respondentes a qualidade do transporte intermunicipal é ruim. Segundo Belanche (2016), cidades inteligentes lidam com domínios fisicamente difíceis, 
mas com investimentos locais em bens públicos, como no sistema de transporte público por exemplo, beneficia os cidadãos incluído grupos vulneráveis como os idosos.

Já a variável que apresentou a maior média foi a disponibilidade de Infraestrutura TIC com média de 3,45, ou seja, a maioria dos respondentes identificou que a população tem acesso a computadores, porém acreditam que o acesso à internet banda larga precisa ser melhorado. De acordo com a Prefeitura de Pindamonhangaba (2020), a cidade possui vários pontos de internet gratuitos em locais públicos como na Praça Monsenhor Marcondes, Praça do Cisas, Praça Pastor José Ezequiel da Silva, no Araretama (em frente à EM Elias Bargis), na praça de eventos do Parque da Cidade e na área da feira livre.

A terceira dimensão analisada foi Ambiente Inteligente que também apresentou o ranking médio abaixo do aceitável de 2,93, de acordo com a tabela 8 . O fator que contribuí para essa média baixa foi 'condições de atratividade natural' $(2,17)$, isso significa que a cidade possui pouquíssimas áreas verdes e há um grau elevado de poluição. De acordo com a Prefeitura de Pindamonhangaba (2020), o município possui três parques municipais: Parque da Cidade, Parque do Itapeva e o Parque Natural Municipal do Trabiju.

Tabela 8 - Análise Descritiva da Dimensão Ambiente Inteligente

\begin{tabular}{|c|c|c|c|c|c|c|}
\hline Característica & $\begin{array}{c}\text { Fatores } \\
\text { (Variável Latente) }\end{array}$ & $\begin{array}{c}\text { Questões } \\
\text { (Variável } \\
\text { Observada) }\end{array}$ & Média & $\begin{array}{l}\text { Desvio- } \\
\text { Padrão }\end{array}$ & $\begin{array}{l}\text { Ranking } \\
\text { Médio do } \\
\text { Fator }\end{array}$ & $\begin{array}{l}\text { Ranking Médio da } \\
\text { Característica }\end{array}$ \\
\hline \multirow{10}{*}{ 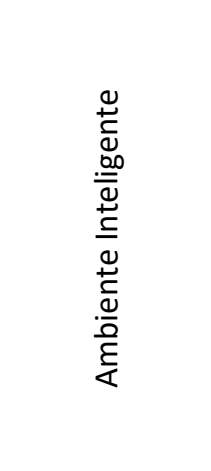 } & \multirow{3}{*}{$\begin{array}{l}\text { Condições de } \\
\text { atratividade } \\
\text { natural }\end{array}$} & Al_01 & 2,77 & 1,42 & \multirow{3}{*}{2,17} & \multirow{10}{*}{2,93} \\
\hline & & Al_02 & 2,98 & 1,38 & & \\
\hline & & Al_03 & 3,00 & 1,43 & & \\
\hline & \multirow{3}{*}{ Poluição } & Al_04 & 3,11 & 1,34 & \multirow{3}{*}{3,13} & \\
\hline & & Al_05 & 3,18 & 1,29 & & \\
\hline & & Al_06 & 3,10 & 1,30 & & \\
\hline & \multirow{2}{*}{$\begin{array}{l}\text { Proteção } \\
\text { ambiental }\end{array}$} & Al_07 & 3,02 & 1,34 & \multirow{2}{*}{3,23} & \\
\hline & & Al_08 & 3,44 & 1,27 & & \\
\hline & \multirow{2}{*}{$\begin{array}{c}\text { Gestão sustentável } \\
\text { de recursos }\end{array}$} & Al_09 & 3,36 & 1,32 & \multirow{2}{*}{3,20} & \\
\hline & & Al_10 & 3,03 & 1,38 & & \\
\hline
\end{tabular}

Fonte: Elaborado pelo autor

Porém, a proteção ambiental apresentou a maior média da dimensão com o valor de 3,23. Deste modo, pode-se dizer que os habitantes de Pindamonhangaba possuem consciência ambiental e tentam aplicar isso no seu dia a dia para tornar a cidade melhor por meio de projetos ambientais.

Um dos projetos ambientais é o Projeto Cubo Ambiente que, de acordo com o Instituto IA3 (2020), é um projeto voltado à criação de consciência ambiental entre os adolescentes de 
Pindamonhangaba por meio de três eixos: oficinas de alfabetização ecológica e educação ambiental; estímulo à coleta seletiva; e, atividades práticas de intervenção e revitalização de áreas degradadas/deterioradas, resgatando a cultura das populações tradicionais, criando vínculos de satisfação e orgulho de residir no bairro.

As ações do projeto estão alicerçadas na tríade do desenvolvimento sustentável, a saber (INSTITUTO IA3, 2020, s.p):

\begin{abstract}
Econômico: atribui valor ao resíduo quando esse é limpo, separado e disposto de forma correta. Os resíduos que antes eram lançados em locais impróprios, promovendo possíveis impactos ambientais negativos e danosos à saúde somando prejuízo público, passam a ser uma fonte de renda alternativa.

Social: a questão da autoestima está relacionada a essa ação. Atribui perspectivas de criar cooperativas ou até mesmo o próprio comércio em materiais recicláveis. Com a diminuição de lixos lançados nas ruas, consequentemente torna o bairro mais agradável. Ambiental: o meio ambiente é sem dúvida beneficiado com a ação promovida pelo Cubo Ambiental. Os resíduos deixam de ser dispostos nos locais impróprios como nos terrenos abandonados, córregos e ruas. Esses passam a ser destinados aos profissionais responsáveis pelo comércio dos materiais (INSTITUTO IA3, 2020, s.p).
\end{abstract}

Para Papa et al. (2013), a preocupação com uso de material reciclado e o consumo consciente de energia não deve ser maior do que a preocupação com a participação do capital humano, ensino e conhecimento do desenvolvimento urbano. No entanto, para Boukela et al. (2016) e Colado et al. (2014), uma cidade é considera inteligente, quando esta pautada no munícipe, que aproveita os conhecimentos e recursos disponíveis de forma sustentável, e fazendo uso de tecnologia de comunicação com o intuito de melhorar os serviços públicos oferecidos, inovando sem comprometer os aspectos econômicos, sociais e ambientais, de modo a melhorar a qualidade de vida do munícipe, nesta linha de pensamento o papel do cidadão participando no processo de transformação da cidade, mesclando o uso de tecnologia e meio ambiente por meio de um governo participativo e interativo completam o conceito.

$\mathrm{Na}$ dimensão Cidadão Inteligente, apresentou um ranking médio aceitável, pois apresentou um valor acima de $3(3,05)$, conforme tabela 9 . A variável que apresentou a menor média foi a 'flexibilidade e criatividade' com uma média de 2,62, ou seja, a população é pouco criativa e baixa facilidade para conseguir emprego de alta qualificação. Komninos (2006) cita que uma população cuja criatividade é construída, por meio de instituições de criação de conhecimentos, infraestrutura digital para gerir e divulgar o conhecimento, forma territórios com alta capacidade de aprendizado e inovação.

Já a variável que apresentou a melhor média foi a 'cidadania e mente aberta' com o valor de 3,39. Isto significa que os habitantes que participaram da pesquisa têm orgulho de morar na cidade e tratam bem os seus visitantes. A penúltima dimensão foi a vida inteligente que 
apresentou um ranking médio aceitável, pois apresentou um valor acima de 3, ou seja, 3,09, conforme a tabela 10 .

Tabela 9 - Análise Descritiva da Dimensão Cidadão Inteligente

\begin{tabular}{|c|c|c|c|c|c|c|}
\hline Característica & $\begin{array}{c}\text { Fatores (Variável } \\
\text { Latente) }\end{array}$ & $\begin{array}{c}\text { Questões } \\
\text { (Variável } \\
\text { Observada) }\end{array}$ & Média & $\begin{array}{l}\text { Desvio- } \\
\text { Padrão }\end{array}$ & $\begin{array}{l}\text { Ranking } \\
\text { Médio do } \\
\text { Fator }\end{array}$ & $\begin{array}{l}\text { Ranking Médio da } \\
\text { Característica }\end{array}$ \\
\hline \multirow{15}{*}{ 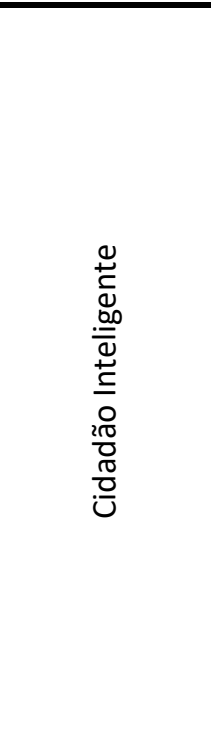 } & \multirow{3}{*}{ Nível de qualificação } & $\mathrm{Cl} 01$ & 3,29 & 1,29 & \multirow{3}{*}{3,31} & \multirow{15}{*}{3,05} \\
\hline & & Cl_02 & 3,16 & 1,30 & & \\
\hline & & Cl_03 & 3,49 & 1,32 & & \\
\hline & \multirow{3}{*}{$\begin{array}{l}\text { Afinidade para } \\
\text { aprendizagem ao } \\
\text { longo da vida }\end{array}$} & Cl_04 & 3,24 & 1,32 & \multirow{3}{*}{3,13} & \\
\hline & & Cl_05 & 3,25 & 1,29 & & \\
\hline & & Cl_06 & 2,89 & 1,32 & & \\
\hline & \multirow{2}{*}{$\begin{array}{l}\text { Social e pluralidade } \\
\text { étnica }\end{array}$} & Cl_07 & 3,03 & 1,30 & \multirow{2}{*}{2,76} & \\
\hline & & Cl_08 & 2,49 & 1,29 & & \\
\hline & Flexibilidade & Cl_09 & 2,67 & 1,26 & \multirow{2}{*}{2,62} & \\
\hline & Criatividade & Cl_10 & 2,58 & 1,28 & & \\
\hline & \multirow{3}{*}{$\begin{array}{l}\text { Cidadania e mente } \\
\text { aberta }\end{array}$} & $\mathrm{Cl} \_11$ & 3,41 & 1,29 & \multirow{3}{*}{3,39} & \\
\hline & & $\mathrm{Cl} \_12$ & 3,37 & 1,25 & & \\
\hline & & $\mathrm{Cl} \_13$ & 3,40 & 1,21 & & \\
\hline & \multirow{2}{*}{$\begin{array}{l}\text { Participação na vida } \\
\text { pública }\end{array}$} & $\mathrm{Cl} \_14$ & 2,96 & 1,34 & \multirow{2}{*}{3,06} & \\
\hline & & $\mathrm{Cl} \_15$ & 3,15 & 1,30 & & \\
\hline
\end{tabular}

Fonte: Elaborado pelo autor

Tabela 10 - Análise Descritiva da Dimensão Vida Inteligente

\begin{tabular}{|c|c|c|c|c|c|c|}
\hline Característica & $\begin{array}{c}\text { Fatores (Variável } \\
\text { Latente) }\end{array}$ & $\begin{array}{c}\text { Questões (Variável } \\
\text { Observada) }\end{array}$ & Média & $\begin{array}{l}\text { Desvio- } \\
\text { Padrão }\end{array}$ & $\begin{array}{c}\text { Ranking Médio } \\
\text { do Fator }\end{array}$ & $\begin{array}{r}\text { Ranking Médic } \\
\text { da Característic }\end{array}$ \\
\hline \multirow{23}{*}{ 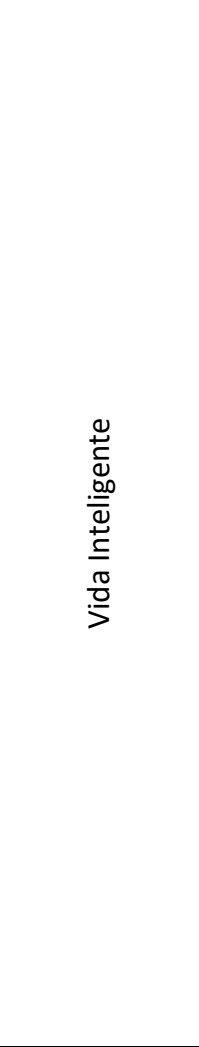 } & \multirow{3}{*}{$\begin{array}{l}\text { Facilidades } \\
\text { culturais }\end{array}$} & VI_01 & 3,56 & 1,31 & \multirow{3}{*}{3,63} & \multirow{23}{*}{3,09} \\
\hline & & VI_02 & 3,76 & 1,32 & & \\
\hline & & VI_03 & 3,56 & 1,31 & & \\
\hline & \multirow{5}{*}{$\begin{array}{l}\text { Condições de } \\
\text { saúde }\end{array}$} & VI_04 & 3,23 & 1,27 & \multirow{5}{*}{2,90} & \\
\hline & & VI_05 & 2,88 & 1,35 & & \\
\hline & & VI_06 & 2,76 & 1,37 & & \\
\hline & & VI_07 & 2,98 & 1,33 & & \\
\hline & & VI_08 & 2,66 & 1,35 & & \\
\hline & \multirow{4}{*}{ Segurança } & VI_09 & 2,61 & 1,26 & \multirow{4}{*}{3,08} & \\
\hline & & VI_10 & 3,38 & 1,37 & & \\
\hline & & VI_11 & 3,19 & 1,31 & & \\
\hline & & VI_12 & 3,12 & 1,31 & & \\
\hline & \multirow{3}{*}{$\begin{array}{l}\text { Qualidade de } \\
\text { moradia }\end{array}$} & VI_13 & 3,18 & 1,27 & \multirow{3}{*}{3,15} & \\
\hline & & VI_14 & 3,06 & 1,25 & & \\
\hline & & VI_15 & 3,22 & 1,26 & & \\
\hline & \multirow{4}{*}{$\begin{array}{l}\text { Facilidade de } \\
\text { educação }\end{array}$} & VI_16 & 3,06 & 1,32 & \multirow{4}{*}{3,21} & \\
\hline & & VI_17 & 3,38 & 1,28 & & \\
\hline & & VI_18 & 3,25 & 1,23 & & \\
\hline & & VI_19 & 3,14 & 1,28 & & \\
\hline & \multirow{2}{*}{ Atração turística } & VI_20 & 2,88 & 1,22 & \multirow{2}{*}{3,13} & \\
\hline & & VI_21 & 3,39 & 1,30 & & \\
\hline & \multirow{2}{*}{ Coesão social } & VI_22 & 2,37 & 1,36 & \multirow{2}{*}{2,56} & \\
\hline & & VI_23 & 2,75 & 1,26 & & \\
\hline
\end{tabular}

Fonte: Elaborado pelo autor 
Já, o fator que apresentou a menor média foi a coesão social com o valor de 2,56, significando que os respondentes acreditam que a taxa é pobreza e a discriminação entre raça e credo são medianas. Esse dado vai de encontro ao Índice de Desenvolvimento Humana (IDHM) desenvolvido pelo Programa das Nações Unidas para o Desenvolvimento (PNUD).

De acordo com PNUD (2010), O IDHM de Pindamonhangaba é 0,773, em 2010, o que situa esse município na faixa de Desenvolvimento Humano Alto (IDHM entre 0,700 e 0,799). A dimensão que mais contribui para o IDHM do município é Longevidade, com índice de 0,843, seguida de Renda, com índice de 0,745, e de Educação, com índice de 0,736. Na tabela 11, apresenta-se a última dimensão da cidade inteligente que é a gestão inteligente que apresentou um ranking médio abaixo do aceitável de 2,55.

Tabela 11 - Análise Descritiva da Dimensão Gestão Inteligente

\begin{tabular}{|c|c|c|c|c|c|c|}
\hline Característica & $\begin{array}{c}\text { Fatores (Variável } \\
\text { Latente) }\end{array}$ & $\begin{array}{c}\text { Questões } \\
\text { (Variável } \\
\text { Observada) }\end{array}$ & Média & $\begin{array}{l}\text { Desvio- } \\
\text { Padrão }\end{array}$ & $\begin{array}{c}\text { Ranking Médio } \\
\text { do Fator }\end{array}$ & $\begin{array}{c}\text { Ranking } \\
\text { Médio da } \\
\text { Característica }\end{array}$ \\
\hline \multirow{10}{*}{ 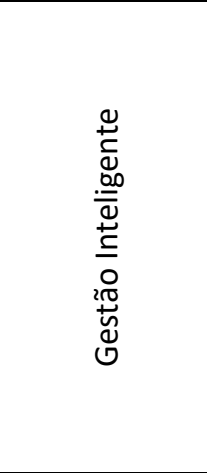 } & \multirow{5}{*}{$\begin{array}{l}\text { Participação na } \\
\text { tomada de } \\
\text { decisão }\end{array}$} & Gl_01 & 2,53 & 1,39 & \multirow{5}{*}{2,54} & \multirow{10}{*}{2,55} \\
\hline & & Gl_02 & 2,38 & 1,39 & & \\
\hline & & Gl_03 & 2,73 & 1,32 & & \\
\hline & & GI_04 & 2,57 & 1,34 & & \\
\hline & & GI_05 & 2,47 & 1,34 & & \\
\hline & \multirow{3}{*}{$\begin{array}{l}\text { Serviços públicos } \\
\text { e sociais }\end{array}$} & GI_06 & 2,78 & 1,37 & \multirow{3}{*}{2,72} & \\
\hline & & Gl_07 & 2,65 & 1,35 & & \\
\hline & & Gl_08 & 2,73 & 1,29 & & \\
\hline & \multirow{2}{*}{$\begin{array}{l}\text { Governança } \\
\text { transparente }\end{array}$} & Gl_09 & 2,73 & 1,36 & \multirow{2}{*}{2,39} & \\
\hline & & GI_10 & 2,06 & 1,14 & & \\
\hline
\end{tabular}

Fonte: Elaborado pelo autor

Ao analisar a participação na tomada de decisão (média de 2,54 ), na percepção dos respondentes, os políticos não representam os interesses da população e não há atividades políticas voltadas ao interesse da população. Em relação ao uso da tecnologia na administração, os respondentes consideraram medianos e segundo eles a prefeitura não atendo os interesses da população assim como não há transparência.

Já os serviços públicos e sociais que apresentou a maior média da dimensão $(2,72)$, os respondentes alegam que os serviços contribuem para a melhoria na qualidade de vida. Os respondentes apontam que o número de creches não atende a necessidade da população e segundo eles o investimento em tecnologia para o ensino público é baixo.

As cidades inteligentes segundo Harrisson et al. (2011) tem como fator chave a possibilidade de tornar visível as abstrações estatísticas do que está acontecendo, e as inovações em TICs potencializam as interações sociais e transformando as relações entre governo, 
academia, setor privado e cidadão, com transparência e prestação de serviços públicos de qualidade (DUTTA et al., 2010; ROMAN, 2010).

Os projetos de cidades inteligentes abordam a questão dos espaços urbanos com foco em ferramentas e dispositivos sem se preocupar com os indivíduos, com benefícios não muito claros aos cidadãos, e como os espaços urbanos sendo compostos por partes física e virtual, exigem uma demanda mais especifica para determinar qual a tecnologia a ser aplicada em determinado problema (BRANCHI et al., 2014; DIAS et al., 2018).

A harmonização entre as partes físicas e virtuais devem ser tratadas de forma harmônica no processo de criação de cidades inteligentes, deve haver todos os subsistemas do sistema urbano, com foco na prestação de serviços e o desenvolvimento social e econômico, capacitando as pessoas para utilizar a tecnologia como fonte de informação, interação e conhecimento, descartando o viés de revolução tecnológica para solução de problemas localizados (NAM et al., 2011; YIGITCANLAR; KANKANAMGE; VELLA, 2020).

Por fim, a governança transparente, com a menor média da dimensão $(2,39)$, para os respondentes a prefeitura não informar e nem disponibiliza serviços via internet e a população não vê o combate a corrupção. Vale ressaltar, que dada a pandemia Covid-19, o município vem trabalhando na implantação de serviços online para o atendimento à população.

4.3 Comparação da Percepção da População de Pindamonhangaba e o Plano Diretor do Município

Após a análise estatística, utilizando a estatística descritiva, elaborou-se uma comparação entre a percepção das dimensões de cidades inteligentes da população de Pindamonhangaba e o plano diretor participativo do município, a Lei Complementar no 03, de 10 de outro de 2006.

O Plano Diretor do Município de Pindamonhangaba é o instrumento básico de política municipal para o desenvolvimento sustentável do meio ambiente urbano e rural, bem como para cumprir a premissa constitucional da garantia das funções sociais da propriedade e do Município (PINDAMONHANGABA, 2006).

Ao analisar a primeira dimensão 'Economia Inteligente', verificou-se que os habitantes percebem como sendo a principal dimensão da cidade inteligente para Pindamonhangaba, pois apresentou o maior ranking médio com o valor de 3,27, conforme apresentado anteriormente. Isto se deve as atividades econômicas que são indústria e comércio. É importante ressaltar, que os respondentes também reconhecem que o município é conhecido pela flexibilidade do mercado do trabalho e pela imagem econômica das empresas que estão instaladas no município. 
Esta percepção está em consonância com o que foi estabelecido no plano diretor do município. Conforme Artigo 47, do Plano Diretor, a política de desenvolvimento econômico no município objetiva a promoção, a racionalização e o pleno emprego dos recursos produtivos, tendo em vista assegurar condições de ocupação e rendimento para a contínua melhoria da qualidade de vida da população (PINDAMONHANGABA, 2006).

Já a mobilidade inteligente se observou um ranking médio de 2.52 . Isto significa que a população reconhece a importância da mobilidade para o município, porém, ainda carece de muitas melhorias principalmente na acessibilidade local. Esse entendimento vai contra o Plano Diretor do município, que no artigo 32 e 33 traz a Política Municipal de Mobilidade Urbana, que trata do movimento que permite as atividades de comunicação, pelo deslocamento de pessoas ou veículos de um ponto a outro dentro do espaço urbano, abrangendo a rede viária, o transporte público e privado, coletivo e individual, bem como os seus espaços complementares.

Ao comparar a percepção dos habitantes e o Plano Diretor de 2006, notou-se que há dissonância, pois, as diretrizes que foram traçadas pelo poder público não se reverteram em ações práticas para a população, ocasionando problemas de acessibilidade local (calçadas, ruas e ciclovias) e transporte público local. A dimensão ambiente inteligente foi ranqueada pelos habitantes que participaram da pesquisa como sendo a quarta dimensão dentro das seis no quesito do ranking médio $(R=2,93)$. Isto significa que para os respondentes o município apresenta problemas principalmente nas condições dos atrativos naturais no que tange ao incentivo do poder público a proteção ambiental, ações de conscientização contra a poluição e comprometimento a saúde dos moradores devido a poluição.

A percepção da população vai contra o que foi estabelecido no Plano Diretor e especificamente no artigo 7ㅇ e 8ㅇ que diz que a Política Municipal do Meio Ambiente objetiva garantir a todos o direito a um ambiente ecologicamente equilibrado, regulando a ação do Poder Público Municipal e sua relação com os munícipes, instituições públicas e privadas constituindo a plataforma de orientação e referência dos agentes para o desenvolvimento sustentável do Município. E, compete ao Poder Público Municipal, com a participação da sociedade civil, garantir o direito ao meio ambiente ecologicamente equilibrado e saudável, para as presentes e futuras gerações.

No que tange a dimensão cidadão inteligente, verificou-se que a população considera a terceira no ranking médio com o valor de 3,05. Isto significa que a população reconhece a importância de os habitantes terem acesso à educação, serem criativos e flexíveis, exercerem 
sua cidadania e serem mentes abertas e haver pluralidade social. O resultado está de acordo com o Plano Diretor que no artigo 55 evidencia a Política Municipal de Educação.

A penúltima dimensão analisada foi a vida inteligente e observou-se que a população reconhece como sendo a segunda no ranking médio com um valor de RM de 3,09 e reconhecem a importância de se ter qualidade de vida para a formação de uma cidade inteligente. Pode-se dizer que os habitantes reconhecem que para que o município de Pindamonhangaba se torne uma cidade inteligente é preciso investir em saúde, facilidades culturais, segurança, qualidade das moradias e coesão social.

A percepção da população que participou da pesquisa está em consonância com o plano diretor no quesito da saúde no artigo 58 e 59 e no que tange a cultura no artigo 64 e 65 . Deste modo, a política municipal de saúde objetiva garantir à população plenas condições de saúde física, social e mental, em consonância com o parágrafo único do artigo 219 , da Constituição do Estado de São Paulo e os artigos 173 a 180, 183 e 184 da Lei Orgânica do Município. Já a política de cultura tem por objetivo incentivar, valorizar, proteger e conservar as diferentes manifestações culturais. A última dimensão analisada foi gestão inteligente. Verificou-se que a dimensão foi a quinta dimensão no ranking médio com o valor de 2,55. Este valor retrata a baixa transparência na governança, principalmente na oferta de serviços públicos via Internet e combate a corrupção.

Dentro deste contexto, ao analisar o Plano Diretor, pode-se dizer que a percepção dos habitantes está de acordo com o planejado no artigo 5 que traz que a gestão da política municipal se pautará pela gestão democrática, assim entendida como processo que garanta a participação dos munícipes de todos os segmentos da população, na sua formulação, execução e acompanhamento. Entretanto, precisam melhorar o acesso das informações públicas pelos portais do município e não foi encontrada nenhuma informação sobre esse quesito.

Resumidamente, ficou claro que o município de Pindamonhangaba apresenta algumas características de cidades inteligentes, no entanto, carece de atualização no Plano Diretor, visto que o atual é de 2006. O município iniciou a atualização do Plano no ano de 2019, contudo, está paralisado devida a pandemia do Covid-19, o que impede as audiências públicas.

\section{Considerações Finais}

Este artigo teve como objetivo diagnosticar as dimensões de cidade inteligente por meio da percepção dos habitantes do município de Pindamonhangaba-SP. Para chegar aos resultados 
obtidos, foi utilizada como recurso uma abordagem quantitativa, por meio da elaboração de um questionário (Survey) estruturado como instrumento de coleta de dados, formado por questões fechadas, divididas em cinco questões socio demográficas relativas ao perfil do respondentes e oitenta questões gerais, adequadas a fatores que identificam uma Cidade Inteligente.

Deste modo e com a confrontação dos resultados obtidos na pesquisa com os resultados, pode-se perceber que o Plano Diretor analisado remente, de forma clara e precisa, a indícios de uma cidade inteligente, mas esses indícios são poucos percebidos por seus habitantes. Pode-se concluir que para melhorar a prestação de serviços à população, além de mudar a visão dos habitantes de Pindamonhangaba, é importante a criação de novas políticas públicas para interação do governo com a população com projetos de uso da tecnologia em serviços prestados à sociedade, como na saúde, na educação, transporte e segurança, entre outros.

$\mathrm{Na}$ área da saúde é importante desenvolver um aplicativo, ou outro meio tecnológico, que permita agendar consultas, autorizar exames, ter acesso aos resultados de exames e entre outros, principalmente em momentos de crise no sistema da saúde gerado pela pandemia do Covid-19 que assola o país e o mundo. É preciso, também, ferramentas tecnológicas para melhorar a qualidade na educação, proporcionar novos caminhos no processo de ensino e aprendizagem, e formar profissionais qualificados, ajudando-os a descobrir estratégias inovadoras para atuar no mercado.

Para tanto, é fundamental que as lideranças políticas, gestores públicos, pesquisadores, organizações da sociedade civil, movimentos sociais e instituições educacionais desenvolvam políticas públicas que contribuam para configurar Pindamonhangaba como uma cidade inteligente. Diante do exposto, espera-se que o conteúdo deste artigo possa contribuir para a produção de projetos futuros por ter alcançado os objetivos propostos, e que possa servir de referência para um aprofundamento em pesquisas no modelo aplicado, inclusive que seja reproduzida em outras cidades das cinco regiões com Brasil.

Mesmo diante da diversidade do país, espera-se que se possa servir de base para elaboração de um modelo brasileiro com dimensões de cidade inteligente, o que não é objeto deste estudo. Por fim, mediante toda a análise da pesquisa, pode-se concluir que os habitantes de Pindamonhangaba não reconhecem a cidade como inteligente.

Apesar de se constituir como uma iniciativa importante para o planejamento urbano e embora tenha sido atingido o objetivo proposto neste trabalho, a pesquisa realizada apresenta limitações. O fator limitante que merece destaque a elaboração do diagnóstico levando em consideração apenas uma percepção, o da população, faltando assim, o poder público. 


\section{Referências}

AHAD, M. A.; PAIVA, S.; TRIPATHI, G.; FEROZ, N. Enabling technologies and sustainable smart cities. Sustainable cities and society, v. 61, p. 102301, 2020.

ALBINO, V.; BERARDI, U.; DANGELICO, R. M. Smart cities: Definitions, dimensions, performance, and initiatives. Journal of urban technology, v. 22, n. 1, p. 3-21, 2015.

ALLAM, Z.; JONES, D. S. Pandemic stricken cities on lockdown. Where are our planning and design professionals [now, then and into the future]?. Land Use Policy, v. 97, 2020.

BABBIE, E. Métodos de pesquisas de survey. Belo Horizonte: Ed. da UFMG, 1999.

BAKICI, T.; ALMIRALL, E.; WAREHAM, J. A Smart City Initiative: The Case of Barcelona. Journal of the Knowledge Economy, v. 2, n. 1, p. 1-14, 2012.

BALLAS, D. What makes a 'happy city'?. Cities, v. 32, p. S39-S50, 2013.

BARRIONUEVO, J. M.; BERRONE, P.; RICART, J. E. Smart Cities, Sustainable Progress. IESE Insight Review, v. 14, p. 50-57, 2012.

BATAGAN, L. Smart cities and sustainability models. Informatica Economica, n. 15, n. 3, pp. 8087, 2011.

BELANCHE, D.; CASALÓ, L. V.; ORÚS, C. City attachment and use of urban services: Benefits for smart cities. Cities, v. 50, p. 75-81, 2016.

BENEVOLO, C.; DAMERI, R. P.; D'AURIA, B. Smart mobility in smart city. In: Empowering Organizations. Springer, Cham, 2016.

BOUSKELA, M.; CASSEB, M.; BASSI, S.; DE LUCA, C.; FACCHINA, M. La ruta hacia las smart cities: Migrando de una gestión tradicional a la ciudad inteligente. Inter-American Development Bank, 2016.

BRANCHI, P. E.; FERNÁNDEZ-VALDIVIELSO, C.; MATIAS, I. R. Analysis Matrix for Smart Cities. Future Internet, v. 6, p. 61-75, 2014.

CARAGLIU, A.; DEL BO, C.; NIJKAMP, P. Smart cities in Europe. Journal of urban technology, v. 18 , n. 2, p. 65-82, 2011.

CHOURABI, H.; NAM, T.; WALKER, S.; GIL-GARCIA, J. R.; MELLOULI, S.; NAHON, K.; SCHOLL, H. J. Understanding smart cities: An integrative framework. In: 2012 45th Hawaii international conference on system sciences. IEEE, 2012. p. 2289-2297.

COLADO, S. et al. (2014). Smart City. Hacia la gestión inteligente. Barcelona: Marcombo. Disponível em:

<https://search.scielo.org/?lang=pt\&count=15\&from=0\&output=site\&sort=\&format=summary $\& f b=\&$ page $=1 \& q=$ cidades+inteligentes $>$ Acesso em: 09 abr 2019.

CRETU, L. G. Smart Cities Design using Event-driven Paradigm and Semantic Web. Informatica Economica, v. 16, n. 4, p. 57-67, 2012.

DIAS, L.C; MORAES, M.B; SILVA, J. L. G; OLIVEIRA, E. A. A. Q.O. Um estudo sobre aspectos de uma cidade inteligente identificados pelos habitantes de São José dos Campos - SP. Revista Brasileira de Gestão e Desenvolvimento Regional, v.14, n.2, 2018.

DUTTA, S. et al. The global innovation index 2011: accelerating growth and development. Fontainebleau: INSEAD, 2011. 
EVANS, J.; KARVONEN, A.; LUQUE-AYALA, A.; MARTIN, C.; MCCORMICK, K.; RAVEN, R.; PALGAN, Y. V. Smart and sustainable cities? Pipedreams, practicalities and possibilities. The International Journal of Justice and Sustainability, v. 24, n. 7, 2019.

GIFFINGER, R. FERTNER, C. KRAMAR, H. KALASEK, R. MILANOVIC, N.P. MEIJERS, E. Smart Cities: Ranking of European Medium-Sized Cities. Vienna, Austria: Centre of Region: 2007

GIFFINGER, R.; HAINDLMAIER, G. Smarter cities ranking: an effective instrument for the positioning of cities? ACE: Architecture, City and Environment, n. 12, p. 7-25, 2010.

HARRISON, C.; DONNELLY, I. A. A theory of smart cities. White Paper, 2011. Disponível em: <http://journals.isss.org/index.php/proceedings55th/article/viewFile/1703/572>. Acesso em: 10 nov 2019.

HERNÁNDEZ-MUÑOZ, J. M.; VERCHER, J. B.; MUÑOZ, L.; GALACHE, J. A.; PRESSER, M.; GÓMEZ, L. A. H.; PETTERSSON, J. Smart cities at the forefront of the future internet. Lecture Notes in Computer Science, n. 6656, p. 447-462, 2011.

HOLLANDS, R.G. Will the real smart city please stand up? Intelligent, progressive or entrepreneurial? City, v.12, n. 3, pp. 303- 320, 28 de nov. de 2008.

IBGE. Instituto Brasileiro de Geografia e Estatística. Censo 2010. Disponível em: $<$ https://cidades.ibge.gov.br/brasil/pesquisa/23/27652?detalhes=true\&localidade1=353800\&lo calidade2=35>. Acesso em: 28 abr. 2019.

INSTITUTO IA3. Sobre a Instituição. Disponível em: <https://www.ia3.org.br/imprensa-ia3/ > Acesso em: 20 mar. 2020.

KOMNINOS, N. The architecture of intelligent cities; integrating human, collective, and artificial intelligence to enhance knowledge and innovation. IN: 2nd INTERNATIONAL CONFERENCE ON INTELLIGENT ENVIRONMENTS, 2006. Anais eletrônicos... Athens: Institution of Engineering and Technology. Disponível em: <http://goo.gl/hHBnR3>. Acesso em: 11 nov. 2019.

LAZAROIU, G. C.; ROSCIA, M. Definition Methodology for the Smart Cities Model. Energy, v. 47, n. 1, p. 326-332, 2012.

LEFEBVRE, H. O direito à cidade.5a edição - 2ª reimpressão -2010 - 3 reimpressão 2011 Editora Centauro. Disponível em:

<https://monoskop.org/images/f/fc/Lefebvre_Henri_O_direito_a_cidade.pdf >. Acesso em: 28 abr. 2019.

LEE, J. H.; PHAAL, R.; LEE, S.-H. An integrated service-device-technology roadmap for smart city development. Technological Forecasting and Social Change, v. 80, n. 2, p. 286-306, 2013.

LOMBARDI, P.; GIORDANO, S.; FAROUH, H.; YOUSEF, W. Modelling the Smart City Performance. Innovation: European Journal of Social Science Research, v. 25, n. 2, p. 37-149, 2012.

LUCAS, A. H.; MORAES, M. B. UM ESTUDO SOBRE AS DIMENSÕES DE CIDADES INTELIGENTES EM TAUBATÉ-SP. Revista Brasileira de Gestão e Desenvolvimento Regional, v. 15, n. 2, 2019.

MARSAL-LLACUNA, M. L.; COLOMER-LLINÀS, J.; MELÉNDEZ-FRIGOLA, J. Lessons in urban monitoring taken from sustainable and livable cities to better address the Smart Cities initiative. Technological Forecasting and Social Change, v. 90, p. 611-622, 2015.

MORAES, M. B.; NETO, R. A. D.; SILVA, G. D. S. S.; CARDOSO, S.; DE OLIVEIRA, M. A. F. N. A Study on the dimensions of sustainable urban development in the perception of the inhabitants of Imperatriz-MA. COLóQUIO-Revista do Desenvolvimento Regional, v. 17, n. 1, p. 139-160, 2020. 
MTE. MINISTÉRIO DO TRABALHO E EMPREGO. Evolução do Emprego Formal em Pindamonhangaba. 2019.

NAM, T.; PARDO, T. A. Conceptualizing smart city with dimensions of technology, people, and institutions. In: Proceedings of the 12th annual international digital government research conference: digital government innovation in challenging times. p. 282-291, 2011.

ODENDAAL, N. Information and communication technology and local governance: understanding the difference between cities in developed and emerging economies. Computers, Environment and Urban Systems, v. 27, n. 6, p. 585-607, 2003.

OLIVEIRA, L. H. Exemplo de cálculo de Ranking Médio para Likert. Notas de Aula. Metodologia Científica e Técnicas de pesquisas em Administração. Mestrado em Adm. E Desenvolvimento Organizacional. PPGA CNEC/FACECA: Varginha, 2005.

PAPA, R.; GARGIULO, C; GALDERISI. A. Towards na urban planners perspective o smart city. Tema Journal of Land Use, Mobility and Environment, v, 6 n. 01, p. 5-17, 2013

PINDAMONHANGABA. Prefeitura de Pindamonhangaba. 2020. Disponível em: <http://www.pindamonhangaba.sp.gov.br/site/ > Acesso em: 28 abr. 2029

. Lei Complementar no 3 de outubro de 2006. Disponível em:

<http://sapl.pindamonhangaba.sp.leg.br/consultas/norma_juridica/norma_juridica_mostrar_pr oc?cod_norma=4494>. Acesso em: 07 jun.2019.

PNUD Brasil Ranking IDHM Municípios. 2010. Disponível em:

<http://www.br.undp.org/content/brazil/pt/home/idh0/rankings/idhm-municipios-2010.html >. Acesso em: 01 jun. 2019.

ROMAN, M. Governing from the middle: the C40 Cities Leadership Group. Corporate Governance, v. 10, n. 1, p. 73-84, 2010.

SARAIVA, C.; MARQUES E. A Dinâmica Social das Favelas da Região Metropolitana de São Paulo, 2007. Revista Pensamento \& Realidade v 21. Disponível em: <https://revistas.pucsp.br/pensamentorealidade/article/view/8306>. Acesso em: 28 abr. 2019.

SCHAFFERS, H.; KOMNINOS, N.; PALLOT, M.; TROUSSE, B.; NILSSON, M.; OLIVEIRA, A. Smart cities and the future internet: towards cooperation frameworks for open innovation. Lecture Notes in Computer Science, n. 6656, p. 431-446, 2011.

SELADA, C.; SILVA, C. As cidades inteligentes na agenda Europeia: Oportunidades para Portugal smart cities in the European agenda: Opportunities for Portugal. In: II Conferência de PRU, VIII ENPLAN e XVIII Workshop APDR:“Europa 2020: retórica, discursos, política e prática. 2014.

SPIEGEL, M. R.; STEPHENS, L. J. Estatística: Coleção Schaum. Bookman, 2000.

TOPPETA, D. The Smart City Vision: How Innovation and ICT Can Build Smart, "Livable", Sustainable Cities. 2010. Disponível em: <http://goo.gl/wXJIK9>. Acesso em: 09 fev. 2019.

UNITED NATIONS. World Urbanization Prospects 2018. Disponível em:

<https://population.un.org/wup/>. Acesso em: 04 ago. 2018.

VELOSA, A. Smart Cities Are the New Revenue Frontier for Technology Providers. 2011. Disponível em: <https://www.gartner.com/doc/1615214/market-trends-smart-cities-new>. Acesso em: 20 out. 2019.

YIGITCANLAR, T.; KAMRUZZAMAN, M.; BUYS, L.; IOPPOLO, G.; SABATINI-MARQUES, J.; DA COSTA, E. M.; YUN, J. J. Understanding 'smart cities': Intertwining development drivers with desired outcomes in a multidimensional framework. Cities, v. 81, p. 145-160, 2018. 
YIGITCANLAR, T.; KANKANAMGE, N.; VELLA, K. How are smart city concepts and technologies perceived and utilized? A systematic geo-twitter analysis of smart cities in Australia. Journal of Urban Technology, p. 1-20, 2020.

WEISS, M. C.; BERNARDES, R. C.; CONSONI, F. L. Cidades inteligentes: casos e perspectivas para as cidades brasileiras. Revista Tecnológica da Fatec Americana, v. 5, n. 1, pp. 01-13, 2017. 